\title{
Restless leg syndrome and migraine: Is there a common etiology?
}

\author{
${ }^{1}$ Gulhan Sarıcam, ${ }^{2}$ Orkun Sarıcam \\ ${ }^{1}$ Department of Neurology Clinic, ${ }^{2}$ Department of Internal Medicine, Ankara Pursaklar State Hospital, \\ Ankara, Turkey
}

\begin{abstract}
Background \& Objectives: Some studies have shown that there is a relationship between restless legs syndrome (RLS) and migraine. Our aim in this study is to investigate the relationship between RLS and migraine and the connection between their etiologies. Methods: This retrospective study was conducted on 109 RLS patients and 105 healthy individuals. Demographic parameters, migraine comorbidity, characteristics of RLS, as well as biochemical and hemogram parameters were examined in the study subjects. Results: The mean age of the RLS patients was $44.28 \pm 10.50$ years and $38.84 \%$ suffered from migraine headaches. RLS was significantly more severe in patients with migraine. Compared to a control group of normal subjects, serum levels of vitamin D, calcium, and iron were significantly lower in RLS patients with or without migraine. The platelet counts, platelet-lymphocyte ratio (PLR), and C-reactive protein (CRP) levels were significantly higher in RLS patients without migraine compared to the control group $(\mathrm{p}<0.05)$

Conclusion: RLS was more severe in patients with comorbid migraine. Vitamin D, calcium, and iron levels were significantly lower and inflammation markers were higher in all RLS patients. We think that further investigation of the underlying mechanisms of these two diseases and the results of populationbased studies will enable clearer diagnosis and effective treatment of RLS and migraine in the future.
\end{abstract}

Keywords: Restless leg syndrome, migraine, iron deficiency, inflammation

\section{INTRODUCTION}

Restless leg syndrome (RLS) is characterized by unpleasant sensations in the leg. RLS sensations typically worsen at night and moving the legs relieves the discomfort. The prevalence of RLS ranges from $4 \%$ to $29 \%$ in North American and Western European Populations. ${ }^{1}$ RLS can be categorized as primary (idiopathic) or secondary. Secondary RLS may coexist with various medical conditions such as diabetes, iron deficiency anemia, depression, anxiety, sleep disorders, Parkinson's disease, and kidney disease. ${ }^{2}$ The pathophysiology of RLS is still partially understood. The most commonly accepted factors associated with RLS include genetic variants, abnormal iron metabolism, dopaminergic dysfunction, and the role of the central opioid system. ${ }^{3}$

Migraine is a common primary headache disorder that affects approximately $10 \%$ to $20 \%$ of the general population, predominantly women. ${ }^{4}$ It presents primarily as unilateral, throbbing headache attacks that are responsive to movement and cause sensitivity to afferent inputs such as visual and auditory stimuli. Migraine significantly affects the quality of life during the peak productive years of an individual. ${ }^{5}$ Studies show that many disorders such as anxiety and depressive disorders, cardiovascular disease, and pain disorders are associated with migraine. ${ }^{6,7}$ Furthermore, it has been shown that the prevalence of RLS is higher in migraine patients compared to individuals without migraine ${ }^{8,9} \mathrm{~A}$ higher prevalence of migraine has also been reported in patients with RLS. ${ }^{10,11}$

The coexistence of RLS and migraine has led researchers to investigate common pathophysiological mechanisms in the etiology. It has been shown that hypothalamic dopaminergic A11 nucleus dysfunction may be involved in RLS. Conversely, dopamine has been shown to be associated with migraine symptoms such as yawning, food cravings, and gastrointestinal disturbances. ${ }^{12,13}$ Similarly, changes in brain iron metabolism are observed in migraine patients

Address correspondence to: Gulhan Saricam, Ankara Pursaklar State Hospital, Department of Neurology Clinic, Mimar Sinan Mah. Çağatay Sok. No :39 Ankara, Turkey. Tel: 050562984 66, Email: gulhansar01 @ hotmail.com

Date of Submission: 11 June 2021; Date of Acceptance: 25 August 2021

https://doi.org/10.54029/2021esm 
and iron deficiency has been shown to be an important component in the pathophysiology of RLS. ${ }^{14}$ Common factors to be determined in the etiology of RLS and migraine may guide the prevention and treatment of these diseases. In this study, we aimed to investigate the frequency of migraine in patients with RLS, the characteristics of RLS, and common biochemical parameters and inflammatory markers that may be involved in the etiology of both conditions. Therefore, we reviewed the studies dealing with this issue and attempted a more comprehensive evaluation of these issues.

\section{METHODS}

This retrospective study was approved by the Ethics Committee of Dr. Abdurrahman Yurtaslan Ankara Oncology Training and Research Hospital (2020-07/683). All study procedures were conducted in accordance with the principles of the Declaration of Helsinki. The study included 139 patients with the diagnosis of RLS who were admitted and followed up to the neurology and internal diseases outpatient clinic in the period between January 2019 and January 2021. Thirty patients were excluded from the study because they had non-migraine headaches. Patients with a diagnosis of RLS were classified according to whether they had migraine or not as RLSWM (RLS with migraine) and RLSWOM (RLS without migraine) groups, respectively. Patients with a history of chronic disease (diabetes, chronic diseases of the liver, kidney, heart, lungs, or the thyroid, or hematologic disorders), immunodeficiency, acute or chronic inflammatory diseases, oncological diseases, thalassemia; pregnant women, patients with a history of infection in the last month, and patients with a history of drug use were excluded. As the control group, 105 healthy individuals were included in the study. These had been seen at the outpatient clinic for check-ups and had no known diseases.

Demographic characteristics and the results of biochemistry tests, hemograms, erythrocyte sedimentation rates (ESR), and CRP levels of both the patient group and the control group were recorded. The neutrophil-lymphocyte ratio (NLR) was calculated by dividing the neutrophil count by the lymphocyte count, The platelet-lymphocyte ratio (PLR) was calculated by dividing the platelet count by the lymphocyte count, and the monocyteHDL-cholesterol ratio (MHR) was obtained by dividing the number of monocytes by the level of HDL. NLR, PLR, and MHR ratios have been used as an inexpensive and easily calculated index to evaluate systemic inflammation in recent years. ${ }^{15,16}$ It has been reported that NLR, PLR and MHR values may lead to diagnosis and prognosis in many systemic diseases such as malignancies, chronic inflammatory diseases, acute myocardial infarction, renal artery stenosis, diabetes mellitus. ${ }^{17,18}$ These ratios were compared between the patient and control groups.

The diagnosis of RLS was made according to the criteria for restless legs syndrome and the diagnosis of migraine was made according to the criteria of the International Classification of Headache Disorders. RLS has 5 essential diagnostic criteria (Table 1). ${ }^{5,19}$ The RLS Severity Rating Scale developed by the International RLS Working Group (IRLSSG) was administered to the patients diagnosed with RLS. The RLS Severity Rating Scale consists of 10 questions. The total score that can be obtained from the scale ranges from 0 to 40 . A score of 1-10 indicates mild disease (Grade 1), 11-20 indicates moderate severity (Grade 2), 21-30 indicates severe disease (Grade 3), and 31-40 indicates very severe disease (Grade 4) ${ }^{20}$ The patients were classified as lower extremity and lower+upper extremity involvement according to their clinical presentation.

\section{Statistical analysis}

Statistical analyses were performed using the IBM SPSS Statistics 23 package software. Frequencies (counts and percentages) and descriptive statistics (mean, standard deviation) were presented for categorical variables.

Numerical variables were analyzed by the Kolmogorov Smirnov normality test; which revealed that the variables were normally distributed. Because the assumption of normal distribution was confirmed, parametric statistical methods were used for statistical analysis. Differences between more than two independent groups were analyzed by One-Way Analysis of Variance (ANOVA). The Tukey multiple comparison test was used when a difference was detected by ANOVA. Relationships between two independent categorical variables were examined by the chi-square test. Statistical significance was evaluated at a value of 0.05 .

\section{RESULTS}

The mean age was $44.28 \pm 10.50,45.76 \pm 11.08$, and $42.30 \pm 11.57$ years in RLSWM, RLSWOM, and control groups, respectively. The results of ANOVA showed that the mean age was not 
Table 1: 2012 revised RLS diagnostic criteria

\section{Essential diagnostic criteria}

1. An urge to move the legs usually but not always accompanied by, or felt to be caused by, uncomfortable and unpleasant sensations in the legs.

2. The urge to move the legs and any accompanying unpleasant sensations begin or worsen during periods of rest or inactivity such as lying down or sitting.

3 The urge to move the legs and any accompanying unpleasant sensations are partially or totally relieved by movement, such as walking or stretching, at least as long as the activity continues.

4. The urge to move the legs and any accompanying unpleasant sensations during rest or inactivity only occur or are worse in the evening or night than during the day.

5. The occurrence of the above features is not solely accounted for as symptoms primary to another medical or a behavioral condition (e.g., myalgia, venous stasis, leg edema, arthritis, leg cramps, positional discomfort, habitual foot tapping).

\begin{tabular}{l}
\hline Specifiers for clinical course of RLS \\
\hline A Chronic-persistent RLS; Symptoms occurring at least twice a week on average for the past year \\
when not treated. \\
B Intermittent RLS; Symptoms occurring less than twice a week on average for the past year when \\
not treated. \\
Specifiers for clinical significance of RLS \\
$\begin{array}{l}\text { The symptoms of RLS/WED cause significant distress or impairment in social, occupational, educational } \\
\text { or other important areas of functioning by their impact onsleep, energy/vitality, daily activities, behavior, } \\
\text { cognition, or mood. }\end{array}$
\end{tabular}

different across groups ( $\mathrm{p}>0.05)$. Of the patients with RLSWM, $29.4 \%$ were women and $14.8 \%$ were men. Of the patients with RLSWOM, 25.5\% were women and $26.2 \%$ were men. (Table 2 ).

The results of the chi-square test showed that RLS severity was significantly different between the 3 groups $(p<0.05)$. RLS was more severe when migraine was present. The frequency of patients with RLS severity of Grade 3-4 was significantly higher in the RLSWM patient group but there were significantly more patients with RLS severity of Grade 1 in the RLSWOM patient group $(\mathrm{p}=0.003)$. No statistically significant association of the coexistence of RLS and migraine was found with extremity involvement ( $\mathrm{p}>0.05)$ (Table 2$)$. There was no statistically significant relationship between the distribution of extremity involvement and the coexistence of RLS and migraine $(\mathrm{p}>0.05)$ (Table 3).

There was a statistically significant difference in the levels of vitamin D, calcium, iron, ferritin, and total iron binding capacity (TIBC) across the groups $(\mathrm{p}<0.05)$. The levels of vitamin $\mathrm{D}$, calcium, and iron levels were statistically lower in the RLSWM and RLSWOM groups compared to the control group. In the RLSWM group, ferritin levels were significantly lower and the TIBC levels were significantly higher compared to the

Table 2: Demographic characteristics of patients by groups

\begin{tabular}{|c|c|c|c|c|c|}
\hline & $\begin{array}{c}\text { RLSWM }(n=54) \\
\text { Mean } \pm \text { SD }\end{array}$ & $\begin{array}{c}\text { RLSWM }(\mathbf{n}=55) \\
\text { Mean } \pm \text { SD }\end{array}$ & $\begin{array}{c}\text { Controls }(n=105) \\
\text { Mean } \pm \text { SD }\end{array}$ & $\mathbf{F}$ & $\mathbf{p}$ \\
\hline \multirow[t]{2}{*}{ Age (years) } & $44.28 \pm 10.50$ & $45.76 \pm 11.08$ & $42.30 \pm 11.57$ & 1.826 & 0.164 \\
\hline & $\mathrm{n}(\%)$ & $\mathrm{n}(\%)$ & $\mathrm{n}(\%)$ & Chi-square & \\
\hline \multicolumn{6}{|l|}{ Gender } \\
\hline Women & $45(29.4)$ & $39(25.5)$ & $69(45.1)$ & 5.444 & 0.066 \\
\hline Men & $9(14.8)$ & $16(26.2)$ & $36(59.0)$ & & \\
\hline
\end{tabular}

F: One-way analysis of variance (ANOVA), RLSWM: Restless leg syndrome with migraine, RLSWOM: Restless leg syndrome without migraine 
Table 3: Clinical features of RLS

\begin{tabular}{lcccc}
\hline & $\begin{array}{c}\text { RLSWM (n=54) } \\
\text { Mean } \pm \text { SD }\end{array}$ & $\begin{array}{c}\text { RLSWOM }(\mathbf{n = 5 5}) \\
\text { Mean } \pm \text { SD }\end{array}$ & Chi-Square & p \\
\hline Severity & $\mathbf{9 \pm 1 6 . 7}$ & $\mathbf{2 5} \pm \mathbf{4 5 . 5}$ & & \\
Grade 1 & $21 \pm 38.9$ & $18 \pm 32.7$ & & $\mathbf{0 . 0 0 3 *}$ \\
Grade 2 & $\mathbf{2 4 \pm 4 4 . 4}$ & $\mathbf{1 2} \pm \mathbf{2 1 . 8}$ & & \\
Garde 3 and 4 & & & & \\
\hline Extremity Involvement & $39 \pm 72.2$ & $42 \pm 76.4$ & 0.245 & 0.621 \\
Lower & $15 \pm 27.8$ & $13 \pm 23.6$ & & \\
Lower+Upper &
\end{tabular}

*: $\mathrm{p}<0,05$. SD: Standard deviation. RLSWM: Restless legs syndrome with migraine, RLSWOM: Restless legs syndrome without migraine

control group $(\mathrm{p}=0.008, \mathrm{p}=0.000)$ (Table 4).

There was a statistically significant difference in platelet counts, PLR, and the levels of HDL, sedimentation, and CRP across the groups $(\mathrm{p}<0.05)$. The platelet count, PLR, and CRP levels were significantly higher in RLSWOM patients compared to the control group. Although HDL levels of the control group were significantly higher than those of RLSWM and RLSWOM groups, MHR was not significantly different across groups. Sedimentation levels of RLSWM and RLSWOM patients were significantly higher than the individuals in the control group $(\mathrm{p}=0.000)$ (Table 5).

\section{DISCUSSION}

Migraine and RLS are common diseases that predominantly affect women. ${ }^{21,22}$ Gupta et al. found a $51.5 \%$ rate of headache in RLS patients; $44.4 \%$ of which were diagnosed with migraine. ${ }^{11}$ Similarly, in our study, $38.84 \%$ of RLS patients had migraine headaches. In our study, the mean age of RLSWM patients was $44.28 \pm 10.50$ years and $83 \%$ were women. Gozubatik et al. found out that the mean age of RLS patients was 50.4 \pm 12.8 years and $67.5 \%$ of patients with comorbid migraine were women. ${ }^{10}$

Studies have shown that the prevalence and severity of RLS increases with advancing age as well as with coexistent mood disorders and sleep impairment. ${ }^{23-25}$ Rhode et al. found that the RLS severity scale scores were higher in patients having both RLS and migraine than in RLS without migraine, but a statistically significant difference was not detected. ${ }^{26}$ In our study, the severity of RLS was significantly higher in RLS patients with migraine. However, in some studies, no association of the severity of RLS was observed with migraine and other primary headaches. ${ }^{11,27}$ In our study, all patients $(n=109)$ had lower extremity involvement and $25 \%(n=28)$ of the patients had both upper and lower extremity involvement. Similarly, in the study of Yeh et al., all patients $(\mathrm{n}=122)$ had RLS complaints in their legs and $35 \%$ of patients had both upper and lower extremity involvement. ${ }^{28}$ Although a

Table 4: Biochemical test results and differences by groups

\begin{tabular}{lcccccc}
\hline & $\begin{array}{c}\text { RLSWM } \\
(\mathbf{n}=\mathbf{5 4}) \\
\text { Mean } \pm \text { SD }\end{array}$ & $\begin{array}{c}\text { RLSWOM } \\
(\mathbf{n = 5 5 )} \\
\text { Mean } \pm \text { SD }\end{array}$ & $\begin{array}{c}\text { Controls } \\
(\mathbf{n = 1 0 5}) \\
\text { Mean } \pm \text { SD }\end{array}$ & $\mathbf{F}$ & $\mathbf{p}$ & Differences \\
\hline Vit D (ng/ml) & $14.72 \pm 5.01$ & $15.17 \pm 7.54$ & $17.93 \pm 7.01$ & 5.351 & $\mathbf{0 . 0 0 5 *}$ & $\mathbf{3 - 1 . 2}$ \\
$\mathrm{Ca}(\mathrm{mg} / \mathrm{dL})$ & $9.38 \pm 0.40$ & $9.38 \pm 0.44$ & $9.89 \pm 0.36$ & 43.404 & $\mathbf{0 . 0 0 0 *}$ & $\mathbf{3 - 1 . 2}$ \\
$\mathrm{Mg}(\mathrm{mg} / \mathrm{dl})$ & $2.00 \pm 0.17$ & $2.01 \pm 0.16$ & $2.02 \pm 0.16$ & 0.258 & 0.773 & - \\
Iron (ug/dl) & $67.1 \pm 39.9$ & $74.1 \pm 31.9$ & $102.2 \pm 41.8$ & 17.900 & $\mathbf{0 . 0 0 0 *}$ & $\mathbf{3 - 1 . 2}$ \\
Ferritin (ng/ml) & $30.3 \pm 26.7$ & $56.6 \pm 68.7$ & $61.7 \pm 67.8$ & 4.981 & $\mathbf{0 . 0 0 8 *}$ & $\mathbf{1 - 3}$ \\
TIBC (ug/dl) & $389.0 \pm 59.3$ & $365.1 \pm 78.6$ & $350.8 \pm 62.6$ & 5.956 & $\mathbf{0 . 0 0 3 *}$ & $\mathbf{1 - 3}$ \\
$\mathrm{B} 12(\mathrm{pg} / \mathrm{mL})$ & $298.0 \pm 88.8$ & $331.2 \pm 119.6$ & $329.2 \pm 114.8$ & 1.695 & 0.186 & - \\
\hline
\end{tabular}

F: One-way analysis of variance (ANOVA), *: p<0.05. RLSWM: Restless legs syndrome with migraine, RLSWOM: Restless legs syndrome without migraine, D vit: vitamin D, Ca: Calcium, Mg: Magnesium, TIBC: total iron binding capacity, B12: vitamin B12 
Table 5: Differences in hematologic parameters, ESR, and CRP and HDL levels by groups

\begin{tabular}{lcccccc}
\hline & $\begin{array}{c}\text { RLSWM } \\
(\mathbf{n}=\mathbf{5 4})\end{array}$ & $\begin{array}{c}\text { RLSWOM } \\
(\mathbf{n}=\mathbf{5 5})\end{array}$ & $\begin{array}{c}\text { Controls } \\
(\mathbf{n}=\mathbf{1 0 5})\end{array}$ & $\mathbf{F}$ & $\mathbf{p}$ & Difference \\
& Avg \pm SD & Avg \pm SD & Avg \pm S.D. & & & \\
\hline WBC $\left(\times 10^{3} \mu \mathrm{l}\right)$ & $6.70 \pm 1.52$ & $7.04 \pm 1.58$ & $6.84 \pm 1.62$ & 0.641 & 0.528 & \\
PLT $\left(\times 10^{3} \mu \mathrm{l}\right)$ & $266.4 \pm 69.0$ & $281.2 \pm 65.7$ & $252.8 \pm 54.5$ & 3.951 & $\mathbf{0 . 0 2 1 *}$ & $\mathbf{2 - 3}$ \\
LYM $\left(\times 10^{3} \mu \mathrm{l}\right)$ & $2.85 \pm 3.06$ & $2.41 \pm 0.69$ & $4.15 \pm 6.96$ & 2.466 & 0.087 & \\
NEU $\left(\times 10^{3} \mu \mathrm{l}\right)$ & $3.45 \pm 1.12$ & $3.83 \pm 1.28$ & $4.19 \pm 5.20$ & 0.705 & 0.495 & \\
MON $\left(\times 10^{3} \mu \mathrm{l}\right)$ & $0.47 \pm 0.18$ & $0.47 \pm 0.21$ & $0.54 \pm 0.97$ & 0.270 & 0.763 & \\
HDL $(\mathrm{mg} / \mathrm{dl})$ & $49.7 \pm 11.9$ & $48.3 \pm 12.7$ & $56.2 \pm 10.4$ & 10.813 & $\mathbf{0 . 0 0 0 *}$ & $\mathbf{3 - 1 . 2}$ \\
NLR & $1.49 \pm 0.68$ & $1.75 \pm 0.94$ & $1.52 \pm 0.63$ & 2.180 & 0.116 & \\
PLR & $115.21 \pm 41.81$ & $127.48 \pm 51.03$ & $105.56 \pm 43.97$ & 4.256 & $\mathbf{0 . 0 1 5 *}$ & $\mathbf{2 - 3}$ \\
MHR & $0.01 \pm 0.00$ & $0.01 \pm 0.01$ & $0.01 \pm 0.02$ & 0.028 & 0.972 & \\
ESR $(\mathrm{mm} / \mathrm{l})$ & $16.7 \pm 9.5$ & $13.9 \pm 7.2$ & $6.9 \pm 3.6$ & 46.761 & $\mathbf{0 . 0 0 0 *}$ & $\mathbf{3 - 1 . 2}$ \\
CRP $(\mathrm{mg} / \mathrm{l})$ & $0.40 \pm 0.63$ & $0.67 \pm 1.96$ & $0.16 \pm 0.18$ & 4.328 & $\mathbf{0 . 0 1 4}$ & $\mathbf{2 - 3}$ \\
Hb $(\mathrm{g} / \mathrm{dl})$ & $13.08 \pm 1.91$ & $13.46 \pm 2.17$ & $15.92 \pm 12.82$ & 2.270 & 0.106 & \\
\hline
\end{tabular}

F: One-way analysis of variance (ANOVA), *: p<0.05, RLSWM: Restless legs syndrome with migraine, RLSWOM: Restless legs syndrome without migraine. WBC: white blood cell, PLT: platelets, LYM: lymphocytes, NEU: neutrophils, MON: monocytes, HDL: high-density lipoprotein, NLR: neutrophil/lymphocyte ratio, PLR: platelet/lymphocyte ratio, MHR: monocyte/HDL ratio, ESR: erythrocyte sedimentation rate, CRP: C-reactive protein, Hb: hemoglobin

relationship was found between the severity of RLS and upper extremity involvement in several previous studies, a significant relationship was not found in our study. ${ }^{29,30}$

Studies in the literature show that the dopaminergic system plays an important role in the pathophysiology of RLS. ${ }^{31}$ It has been reported that vitamin D acts on the nigrostriatal dopaminergic pathway by increasing the levels of dopamine or its metabolites and protecting dopaminergic neurons against toxins. ${ }^{32}$ In patients with migraine, it has been suggested that vitamin D deficiency aggravates neuroinflammation and that the neuronal hypersensitivity in hypocalcemia may increase the severity of migraine attacks by contributing to sensory symptoms of migraine. ${ }^{33,34}$ In our study, the levels of vitamin $\mathrm{D}$, calcium, and iron were significantly lower in patients with RLSWM and RLSWOM compared to the control group. Similarly, Wali et al. showed that vitamin $D$ and ferritin values of patients with RLS were significantly lower than those of the control group. ${ }^{35}$ In another study, hypocalcemia and vitamin $\mathrm{D}$ deficiency were found to be associated with migraine attacks and loss of function in migraine. ${ }^{36}$

Iron deficiency affects many cellular functions and processes including oxygen delivery, electron storage and transport, oxidative phosphorylation, neurotransmitter metabolism, immune function, and DNA synthesis. ${ }^{37}$ Previous studies have shown that RLS is associated with iron deficiency anemia and that the symptom severity in RLS is associated with serum ferritin levels. ${ }^{14,38}$ Furthermore, it has been shown that iron plays an important role in the synthesis of serotonin, dopamine, and norepinephrine, and that serotonin levels are associated with migraine..$^{39,40}$ In our study, the iron levels of the patients with RLS were found to be lower than those of the control group. In the RLSWM group, ferritin levels were lower and TIBC was higher. The presence of more severe iron deficiency and more severe RLS in patients with RLSWM suggests the presence of a common etiology.

The inflammatory or infectious character of the factors that have been associated with RLS suggests that systemic inflammation has an etiological role to play. ${ }^{41}$ In the migraine pathogenesis, neurogenic inflammation is involved along with the contribution of oxidative stress, cytokines, and vasomotor changes. ${ }^{42}$ In our study, sedimentation levels were found to be significantly higher in all patients with RLS compared to the control group. Yazar et al. found a higher neutrophil count and NLR, PLR, and MLR values in migraine patients compared to the control group. ${ }^{43}$ In another study, Varım et al. found a significantly higher NLR value in patients with RLS. ${ }^{44}$ In our study, the platelet 
count, PLR, and CRP levels were higher in the RLSWOM group compared to the control group.

In conclusion, we have shown in our study that migraine occurs at significantly higher rates in patients with RLS. We found that RLS was more severe in patients having concurrent RLS and migraine. We found that the levels of vitamin $\mathrm{D}$, calcium, and iron were significantly lower and inflammation markers were higher in all patients diagnosed with RLS. In the group with RLS and migraine, iron deficiency and RLS were more severe compared to the RLS group without migraine. These results provide important information about the common points in the physiopathology of RLS and migraine. We think that further investigation of the underlying mechanisms of both diseases and the results of population-based studies will enable more effective diagnosis and treatment of these diseases in the future.

\section{DISCLOSURE}

Financial support: None

Conflict of interest: None

\section{REFERENCES}

1. Schürks M, Winter A, Berger K, Kurth T. Migraine and restless legs syndrome: A systematic review. Cephalalgia 2014;34(10):777-94.

2. Szentkirályi A, Völzke H, Hoffmann W, Trenkwalder C, Berger K. Multimorbidity and the risk of restless legs syndrome in 2 prospective cohort studies. Neurology 2014;82:2026-33

3. Guo S, Huang J, Jiang H, et al. Restless legs syndrome: From pathophysiology to clinical diagnosis and management. Front Aging Neurosci 2014;9:171.

4. Stovner LJ, Andree C. Prevalence of headache in Europe: a review for the Eurolight project. $J$ Headache Pain 2010;11:289-99.

5. Headache Classifcation Committee of the International Headache Society. The international classifcation of headache disorders, 3rd edition (beta version). Cephalalgia 2013; 33(9):629-808.

6. Tietjen GE, Brandes JL, Peterlin BL, et al. Allodynia in migraine: association with comorbid pain conditions. Headache 2009;49:1333-44.

7. Schürks M, Rist PM, Bigal ME, Buring JE, Lipton RB, Kurth T. Migraine and cardiovascular disease: systematic review and meta-analysis. $\mathrm{Br}$ Med $\mathrm{J}$ 2009;339:b3914.

8. Zanigni S, Giannini G, Melotti R, et al. Association between restless legs syndrome and migraine: a population-based study. Eur J Neurol 2014;21:120510.

9. Lucchesi C, Bonanni E, Maestri M, Siciliano G, Murri L, Gori S. Evidence of increased restless legs syndrome occurrence in chronic and highly disabling migraine. Funct Neurol 2012;27:91-4.
10. Gozubatik-Celik G, Benbir G, Tan F, Karadeniz $\mathrm{D}$, Goksan B. The prevalence of migraine in restless legs syndrome. Headache 2014;54:872-7.

11. Gupta R, Lahan V, Goel D. Primary headaches in restless legs syndrome patients. Ann Indian Acad Neurol 2012;15:104-8.

12. Paulus W, Dowling P, Rijsman R, Stiasny-Kolster K, Trenkwalder C, de Weerd A. Pathophysiological concepts of restless legs syndrome. Mov Disord 2007;22:1451-6.

13. Charbit AR, Akerman S, Goadsby PJ. Dopamine: what's new in migraine? Curr Opin Neurol 2010; 23: 275-81.

14. Mizuno S., Mihara T., Miyaoka T., Inagaki T., Horiguchi J. CSF iron, ferritin and transferrin levels in restless legs syndrome. J Sleep Res 2005;14:43-7.

15. Feng JR, Qiu X, Wang F, et al. Diagnostic value of neutrophil-to-lymphocyte ratio and platelet-tolymphocyte ratio in Crohn's disease. Gastroenterol Res Pract 2017;2017:3526460.

16. Cetin MS, Ozcan Cetin EH, Kalender E, et al. Monocyte to HDL cholesterol ratio predicts coronary artery disease severity and future major cardiovascular adverse events in acute coronary syndrome. Heart Lung Circ 2016;25(11):1077-86.

17. Marin Hernandez C, Pinero Madrona A, Gil Vazquez PJ, et al. Usefulness of lymphocyte-tomonocyte, neutrophil-to-monocyte and neutrophilto-lymphocyte ratios as prognostic markers in breast cancer patients treated with neoadjuvant chemotherapy. Clin Transl Oncol 2018;20(4):476-83.

18. Liu H, Zhan F, Wang Y. Evaluation of monocyteto-high-density lipoprotein cholesterol ratio and monocyte-to-lymphocyte ratio in ischemic stroke. J Int Med Res. 2020;48(7): 0300060520933806

19. International Restless Legs Syndrome Study Group. IRLSSG Diagnostic Criteria for RLS.2012; Available at: www.irlssg.org [Google Scholar]

20. Walters AS, LeBrocq C, Dhar A, et al. Validation of the International Restless Legs Syndrome Study Group rating scale for restless legs syndrome. Sleep Med 2003;4(2):121-32.

21. Haut SR, Bigal ME, Lipton RB. Chronic disorders with episodic manifestations: focus on epilepsy and migraine. Lancet Neurol 2006;5:148-57.

22. Innes KE, Selfe TK, Agarwal P. Prevalence of restless legs syndrome in North American and Western European populations: a systematic review. Sleep Med 2011;12:623-34.

23. Phillips B, Young T, Finn L, et al. Epidemiology of restless legs syndrome in adults. Arch Intern Med 2000;160:2137-41.

24. Ohayon MM, Roth T. Prevalence of restless legs syndrome and periodic leg movement disorder in the general population. J Psychosom Res 2002;53:547-54.

25. Innes KE, Flack KL, Selfe TK, Kandati S, Agarwal P. Restless legs syndrome in an Appalachian primary care population: prevalence, demographic and lifestyle correlates, and burden. J Clin Sleep Med 2013;9(10):1065-75.

26. Rhode AM, Hösing VG, Happe S, Biehl K, Young P, Evers S. Comorbidity of migraine 
and restless legs syndrome: a case-control study. Cephalalgia 2007;27:1255-60.

27. Fernández-Matarrubia M, Cuadrado ML, SánchezBarros CM, et al. Prevalence of migraine in patients with restless legs syndrome: a case-control study. Headache 2014;54:1337-46.

28. Yeh P, Ondo WG, Picchietti DL, et al. Depth and distribution of symptoms in restless legs syndrome/ Willis-Ekbom disease. J Clin Sleep Med 2016;12(12):1669-80.

29. Michaud M, Chabli A, Lavigne G, Montplaisir J. Arm restlessness in patients with restless legs syndrome. Mov Disord 2000; 15:289-93.

30. Tison F, Crochard A, Leger D, Bouee S, Lainey E, El Hasnaoui A. Epidemiology of restless legs syndrome in French adults: a nationwide survey: the INSTANT Study. Neurology 2005;65:239-46.

31. Trotti LM, Bhadriraju S, Rye DB. An update on the pathophysiology and genetics of restless legs syndrome. Curr Neurol Neurosci Rep 2008;8(4):2817.

32. Ibia M, Sawadab H, Nakanishia M, et al. Protective effects of 1,25-(OH)2D3 against the neurotoxicity of glutamate and reactive oxygen species in mesencephalic culture. Neuropharmacology 2001;40:761-71.

33. Yilmaz IA, Ozge A, Erdal ME, Edgunlu TG, Cakmak SE, Yalin OO. Cytokine polymorphism in patients with migraine: Some suggestive clues of migraine and inflammation. Pain Med (Malden Mass.) 2010;11:492-7.

34. Khan M, Sharma S. StatPearls. StatPearls Publishing LLC; Treasure Island, FL, USA: 2019. Physiology, parathyroid hormone (PTH)

35. Wali S,Alsafadi S,Abaalkhail B, et al. The association between vitamin D level and restless legs syndrome: A population-based case-control study. J Clin Sleep Med 2018;14(4):557-64.

36. Patel U, Kodumuri N, Malik P, et al. Hypocalcemia and vitamin $\mathrm{D}$ deficiency amongst migraine patients: A nationwide retrospective study. Medicina (Kaunas) 2019;55(8):407.

37. Pamuk GE, Top MS, Uyanik MS, et al. Is irondeficiency anemia associated with migraine? Is there a role for anxiety and depression? Wien Klin Wochenschr 2016;128(8):576-80.

38. Koo BB, Bagai K, Walters AS. Restless legs syndrome: Current concepts about disease pathophysiology. Tremor Other Hyperkinet Mov (N Y) 2016;6:401.

39. Deen M, Christensen CE, Hougaard A, Hansen HD, Knudsen GM, Ashina M. Serotonergic mechanisms in the migraine brain-a systematic review. Cephalalgia 2017;37(3): 251-64.

40. Tayyebi A, Poursadeghfard M, Nazeri M, Pousadeghfard T. Is there any correlation between migraine attacks and iron deficiency anemia? A Case-control study. Int J Hematol Oncol Stem Cell Res 2019;13(3):164-71.

41. Weinstock LB, Walters AS, Paueksakon P. Restless legs syndrome - Theoretical roles of inflammatory and immune mechanisms. Sleep Med Rev 2012;16(4):34154.

42. Karabulut KU, Egercioglu TU, Uyar M, Ucar Y.
The change of neutrophils/lymphocytes ratio in migraine attacks: A case-controlled study. Ann Med Surg (Lond) 2016;10:52-6.

43. Yazar HO, Yazar T, Aygün A, Kaygisiz Ş, Kirbaş D. Evaluation of simple inflammatory blood parameters in patients with migraine. Ir J Med Sci 2020;189(2):677-83.

44. Varım C, Acar BA, Uyanık MS, et al. Association between the neutrophil-to-lymphocyte ratio, a new marker of systemic inflammation, and restless legs syndrome. Singapore Med J 2016;57(9):514-6. 